\title{
GIOVANNI PONTIERO, TRADUTOR DE SARAMAGO ${ }^{1}$
}

\section{Lenita Rimoli Esteves*}

RESUMO: Este trabalho mostrará os primeiros resultados de uma pesquisa sobre as traduções dos romances de José Saramago para a lingua inglesa. Em termos gerais, a pesquisa busca articular informações sobre a recepção das obras de Saramago nos países de língua inglesa e a intermediação realizada pelos tradutores nesse processo. Especificamente, este trabalho buscará relatar qual foi o espaço dado ao tradutor na grande repercussão das obras de Saramago em nivel internacional, quais eram as relações do tradutor com o autor e como outras atividades e ocupações de Giovanni Pontiero se integravam à atividade de tradução.

UNITERMOS: Giovanni Pontiero; José Saramago; tradução literária.

ABSTRACT: This paper will show the first results of an ongoing research about the translations of José Saramago's works into English. Generally speaking the research aims at collecting information about the reception of the Portuguese novelist's works in English speaking countries, so as to investigate the intermediating role played by translators in this process. This work will specifically focus on translator Giovanni Pontiero's influence on Saramago's

1 Uma versão preliminar deste trabalho foi apresentada em comunicação no Simpósio Tradução, adaptação e intermediações culturais, durante o XI Congresso Internacional da ABRALIC, na semana de 13 a 17 de julho de 2008.

Professora do Departamento de Letras Modernas da FFLCH - USP. 
works reception on a global level. It will also show some other activities developed by Pontiero along with his work as a translator, in order to show how they integrate and complement each other.

KEYWORDS: Giovanni Pontiero; José Saramago; literary translation.

\section{Introdução}

Costumam dizer que o tradutor é um leitor especial, privilegiado, que tem uma visão ampla das obras com que trabalha. Dizem também que Brasil e Portugal falam a mesma língua, e de certa forma isso é inegável. Este trabalho nasceu principalmente de uma curiosidade. Como seria o "sabor" do texto saramaguiano traduzido para o inglês? Outra questão que surgia, na esteira dessa primeira: em que medida as obras que ganharam o prêmio Nobel de Literatura em 1998 foram as obras de Saramago em inglês? Teria o tradutor dado alguma contribuição para essa conquista? Claro que sim, numa resposta a uma pergunta que se pretendesse inocente: é óbvio que o acesso às literaturas de línguas menos difundidas no mundo é feito, no caso do Nobel, por meio de traduções em lingua inglesa. Mas, se a pergunta for maliciosa: em que medida a tradução para o inglês "configurou" o texto de Saramago para que ele pudesse ser um indicado ao prêmio?

Será essa uma pergunta cabível? Para alguns sim. Segundo Eoyang (2003:73), muitos (dentre eles o escritor Garcia Márquez) concordam que a tradução feita por Gregory Rabassa das obras de Garcia Márquez (principalmente Cem anos de solidão) colaborou para que o autor ganhasse o Nobel de literatura. O próprio Rabassa comenta a observação de Márquez (tomada, por aquele, como "estapafúrdia"), segundo a qual Márquez teria gostado mais do texto em inglês do que do original em espanhol (Rabassa, 2005:96).

Em relação às traduções de Saramago para o inglês, o que mais me chamava a atenção era uma posição de certa forma privilegiada. Não seria a mesma coisa que analisar as traduções de obras brasileiras para o inglês. A cultura lusitana está mais longe de nós. Aliás, parte do encanto das obras de Saramago é justamen-

TradTerm, 15, 2009, p. 11-24 
te uma leitura que traz Portugal para mais perto. Os textos de Saramago têm um sabor inegavelmente português. Vários personagens de várias histórias vagam por Lisboa como um Leopold Bloom lusitano ${ }^{2}$, despertando no leitor uma curiosidade pelos cantos, recônditos, monumentos e praças lisboetas.

Além disso, os termos portugueses que se diferenciam dos brasileiros ("sala-de-banhos" para "banheiro"; "mulher a dias" para "faxineira"; "telemóvel" para "celular"; "um duche" para "uma sanduíche") trazem também esse sabor diferente. Essa sensação que nós, brasileiros, podemos sentir lendo o texto de Saramago não está acessivel para falantes do inglês. As diferenças são muito sutis e, para alguém que não faz parte de uma comunidade falante do português, trata-se apenas de uma substituição de palavras.

Por outro lado, não podemos nos esquecer da contrapartida. Será que nós percebemos o sabor de um texto em inglês que foi escrito numa cultura, mas circula em outra? Talvez sim, talvez não. Isso mais uma vez corrobora a ideia de que nossa situação e nosso contexto determinam a leitura que fazemos de um texto. E não é só na tradução que isso acontece, mas em qualquer ato de leitura.

Em busca de mais informações sobre as traduções, acabei conhecendo mais a fundo características do tradutor Giovanni Pontiero, que traduziu sete obras de Saramago. O escritor só ganhou outro tradutor em língua inglesa após a morte de Pontiero, em 1996, aos 64 anos.

Giovanni Pontiero tinha ascendência italiana, mas nasceu e foi criado em Glasgow, na Escócia. Cursou a Glasgow University, onde estudou espanhol, italiano e Estudos Latino-Americanos. Na década de 1960 veio para o Brasil, onde passou dois anos como professor da Universidade Federal da Paraíba (Griffing, 1996). As sete obras de Saramago que ele traduziu são: Memorial do convento (lançado em inglês em 1987); $O$ ano da morte de Ricardo Reis (lançado em inglês em 1991); O Evangelho segundo Jesus Cristo (lançado em inglês em 1993); Manual de pintura e caligrafia (lançado em inglês em 1994); Jangada de pedra (lançado em inglês em 1994); A

2 A sugestão da semelhança entre o personagem joyciano e alguns personagens de Saramago é de Chris Rollason (1998).

TradTerm, 15, 2009, p. 11-24 
história do cerco de Lisboa (lançado em inglês em 1996); e Ensaio sobre a cegueira (lançado em inglês em 1997). Houve ainda uma reedição de Memorial do convento, devido a correções feitas pela editoração as quais o autor repudiou. Quem restabeleceu o texto ao seu formato anterior também foi Giovanni Pontiero.

Durante um longo período de sua vida, após retornar do Brasil, Pontiero atuou na Manchester University como professor de Estudos Latino-Americanos. Escreveu vários livros sobre autores da literatura brasileira e também traduziu obras de Clarice Lispector. Com o lançamento de Memorial do convento, Saramago ganhou reconhecimento internacional, principalmente por meio da tradução de Pontiero (o título em inglês é Baltasar and Blimunda). Por sua vez, Pontiero ganhou importantes prêmios de tradução, principalmente pelas versões que fez da obra de Saramago. Após a sua morte, os livros de Saramago têm sido geralmente traduzidos por Margaret Jull Costa.

Pontiero afirmou certa vez que a posição mais confortável para um tradutor é a do acadêmico, do professor universitário. Nesse ambiente, segundo ele, é possível realizar uma tradução cuidadosa, sem as pressões de tempo e dinheiro que assolam o dia a dia dos tradutores "normais" (Pontiero, 1997b:63). O ambiente acadêmico proporciona, acrescenta o autor, a possibilidade de realizar uma tradução enraizada na pesquisa. É o contrário do que Milton classificou como "tradução de fábrica" (Milton, 2002:81 et passim). De fato, só num ambiente desses seria possivel dedicar tanto tempo e esforço a uma tradução. Pontiero tinha uma relação bem próxima com Saramago, e os dois trocaram correspondências sobre as dúvidas do tradutor a respeito das obras que estavam sendo traduzidas.

A escolha de Pontiero como tradutor de Saramago ocorreu, em certo sentido, na direção inversa: pode-se dizer que foi Pontiero quem "escolheu" traduzir Saramago. Em geral, um editor, após selecionar obras a serem traduzidas, busca um tradutor para realizar o trabalho. No caso de Saramago-Pontiero não foi assim. No outono de 1985, um editor londrino que buscava autores estrangeiros, ao voltar da Feira do Livro de Frankfurt, enviou a Pontiero vários romances, a fim de que ele os avaliasse para uma possivel publicação em inglês. Entre esses romances estava Memorial do convento (Sager, 1997:111). Pontiero gostou do livro e insistiu com

TradTerm, 15, 2009, p. 11-24 
o editor para que o publicasse, enviando um capítulo traduzido para convencê-lo da excelência de Saramago.

Juan C. Sager foi colega de Pontiero na Manchester University, e nos dá ricas informações sobre Pontiero e sua relação com Saramago. Este último referiu-se a sua relação com Pontiero como "um diálogo fraterno" e um "encontro tão fértil", a partir do qual nasceu e durou uma profunda relação de trabalho e amizade" (Sager, 1997:119). O processo da tradução de Memorial do convento foi considerado por Saramago como "uma aventura humana e literária fora do comum" (idem, ibidem:112).

Entretanto, há no texto de Sager algo mais interessante: uma preocupação de Pontiero justamente com o aspecto comentado no início deste trabalho, qual seja aquilo que há de especificamente lusitano nas obras de Saramago, e como lidar com isso nas traduções. Segundo nos narra Sager, em várias das obras Pontiero julgava correto definir as estratégias de tradução a partir do público-leitor. No caso de Ensaio sobre a cegueira, por exemplo, Pontiero estabeleceu que a ênfase devia recair na universalidade da alegoria, o que exigia uma estratégia de "neutralidade cultural" por parte do tradutor. Ao mesmo tempo, em Viagem a Portugal, seria preciso decidir se a obra se apresentaria como um livro de viagens (ou seja, uma reflexão pessoal do autor) ou como um guia para leitores interessados na cultura portuguesa (Sager, 1997:112-3).

Frases que parecem ou são provérbios em português precisam de invenções semelhantes em inglês. Mas no caso da neutralidade cultural de Ensaio sobre a cegueira, os provérbios ingleses precisavam ser cuidadosamente escolhidos, para não darem a impressão de que a história se passava no mundo anglófono (idem, ibidem:115). Sager aponta que, apesar da intenção de Saramago de criar um ambiente "neutro" em Ensaio sobre a cegueira, seria muito natural que no original os leitores portugueses encontrassem provérbios, metáforas ou analogias tipicamente portuguesas sem sentir que o romance estava localizado num país lusófono (idem, ibidem:116). Nas palavras de Sager,

Todavia, em uma tradução inglesa não se tratava simplesmente de criar um ambiente linguístico tipicamente inglês - isso poderia dar a impressão de que Saramago

TradTerm, 15, 2009, p. 11-24 
queria localizar o romance na Inglaterra - nem tampouco se poderia dar ao leitor a impressão de que a ação do romance ocorre em um tempo e um lugar sem relação alguma com sua própria realidade, porque isso negaria a natureza alegórico-didática no livro. (Sager, 1997:116) ${ }^{3}$

Ou, nas palavras do próprio Saramago: "Apesar de eu dizer que a história que contei não está localizada, as expressões me denunciam" (Saramago, apud Sager, 1997:118). O "problema" é que Saramago não apenas usa os provérbios portugueses, mas os reverte. Essa reversão só terá o efeito desejado se o provérbio, enraizado numa tradição oral, for conhecido. Assim, talvez se perca, no texto em inglês, apesar dos cuidados de autor e tradutor, o tom irônico desse narrador tão característico de Saramago:

...não quero que fiques para aí como uma burra à nora... [...Going round and round in circles...] (Blindness, p. 85, apud Sager, 1997:116)

Nesse caso, temos uma expressão portuguesa que quer dizer "andar em círculos". A "nora", termo de origem árabe, é "um engenho para tirar água de poços ou cisternas, composto de uma roda que faz girar a corda a que estão presos alcatruzes" (Houaiss, 2008 , versão eletrônica). Em geral quem aciona a nora são burros, que ficam girando em círculos para que os alcatruzes (termo regionalista português que se refere a "cada um dos vasos que, presos à roda da nora, servem para tirar água de poços etc" (idem, ibidem), retirem a água dos poços. Vemos que aqui Pontiero realmente objetivou a neutralização do texto, substituindo uma frase feita (adaptada, com o substantivo "burra", porque o personagem que fala se dirige a uma mulher) da linguagem popular portuguesa por uma expressão menos marcada culturalmente. Passemos ao segundo exemplo:

${ }^{3}$ Todas as citações foram traduzidas pela autora do trabalho.

TradTerm, 15, 2009, p. 11-24 
... já se sabe, água mole em brasa viva tanto dá até que apaga, a rima que a ponha outro... (Ensaio sobre a cegueira, p. 213)

[...as everybody knows, a constant drop hollows a stone, let someone else make it rhyme.] (Blindness, p. 213, apud Sager, 1997:115)

Aqui temos um provérbio bem conhecido também do brasileiro, mas para o qual Pontiero não encontrou correspondente em inglês. Ele então "traduziu", mas sem promover o deslocamento realizado em português. Em português, o narrador desvia o provérbio, contando com um conhecimento partilhado com o leitor. Pontiero provavelmente julgou que, não conhecendo o provérbio, o leitor em inglês não perceberia o desvio. No terceiro exemplo, abaixo, nota-se que o tradutor substituiu o provérbio e tentou deslocá-lo, mas o efeito, parece-nos, fica mais fraco porque, na substituição, muda-se de uma metáfora mais concreta ("fazer das tripas coração") para uma imagem mais abstrata ("taking one's courage in both hands"):

...a isto chama o vulgo fazer das tripas coração, fenômeno de conversão visceral que só na espécie humana tem sido observado. (Ensaio sobre a cegueira, p. 41)

... and this is commonly known as taking one's courage in both hands, a phenomenon that has only been observed in the human species (Blindness, p. 41, apud Sager, 1997:115)

Perde-se então a observação sobre a "conversão visceral", que subverte diretamente o provérbio e, em seu lugar, temos apenas um "fenômeno".

A título de resposta às indagações iniciais colocadas neste trabalho, podemos ver por esses exemplos que inevitavelmente a tradução, por estar inserida numa cultura diferente e, principalmente, por ser escrita numa língua diferente, não proporciona as mesmas possibilidades de interpretação, de associações afetivas e do estabelecimento de relações com tradições inscritas na própria

TradTerm, 15, 2009, p. 11-24 
língua do que as proporcionadas pela cultura e pela língua originais. A constatação é óbvia, mas é importante observarmos como Pontiero estava plenamente ciente dessa transposição, e lidava com ela sem aquelas lamentações que alguns tradutores insistem em repetir, sobre o status inferior de seu trabalho.

\section{0 tradutor segundo Pontiero}

Giovanni Pontiero entendia claramente suas várias funções como tradutor. Mesmo levando em conta o fato de ele fazer parte de uma cultura hegemônica, não é desprezível o fato de Pontiero considerar o tradutor como um agente cultural, que tem maneiras de influir nos rumos da cultura onde está inserido. A seguir, indico de forma sumária as funções que Pontiero sugere que um tradutor pode assumir:

\subsection{0 tradutor como critico e consultor}

Já foi mencionado de passagem que foi Giovanni Pontiero, em 1985, que indicou Memorial do convento para ser traduzido. Em 1987 e 1988, a tradução foi lançada nos Estados Unidos e na Inglaterra, respectivamente, ganhando reconhecimento mundial. O próprio Pontiero nos narra o episódio:

\footnotetext{
Os editores precisam de leitores em lingua estrangeira para que os aconselhem sobre a adequação de publicar uma tradução para o mercado de língua inglesa. Certa vez, sendo solicitado a fazer uma avaliação de vários romances portugueses, descobri Memorial do convento, de Saramago. Gostei imediatamente do romance e escrevi uma avaliação entusiasmada, depois do que o editor me ofereceu um contrato de tradução. (Pontiero, 1997a:18)
}

Mas a indicação feita pelo tradutor deve ser informada, ou seja, o tradutor não deveria considerar apenas a qualidade da obra, mas a probabilidade de ela ser bem aceita na cultura-alvo. Segundo Pontiero, o tradutor deve estar informado sobre a cena literária de sua cultura, suas tendências e gostos, de modo a levá-los em con-

TradTerm, 15, 2009, p. 11-24 
sideração em seu trabalho. Nas palavras de Pontiero, "se o tradutor não conhece a cena, ele não pode considerá-la” (Pontiero, 1997a:22).

No caso de O ano da morte de Ricardo Reis, o próprio Saramago questionou a receptividade da obra em inglês, dados seus traços fortemente lusitanos. Segundo Pontiero:

Quando uma tradução para o inglês do livro foi finalmente encomendada, o próprio Saramago começou a questionar as chances de ele causar alguma impressão nos leitores do mundo de fala inglesa, porque $O$ ano da morte de Ricardo Reis não só é seu romance mais pessoal escrito até o momento, mas também tão firmemente enraizado no legado cultural de Portugal que exige mais que uma curiosidade passageira sobre esse país relativamente pequeno com um passado prodigioso. (Pontiero, 1997b:72)

No final das contas, a recepção foi bastante positiva, mas Pontiero comenta que a maioria dos resenhistas e críticos não tinha acesso ao português e, portanto, fizeram suas análises a partir do texto em inglês. Além disso, os críticos muitas vezes não tinham acesso às declarações de Saramago, o que criou uma série de malentendidos. O escândalo causado por O evangelho segundo Jesus Cristo, escândalo esse alavancado pelas autoridades portuguesas, talvez pudesse ter sido diluído se mais críticos e resenhistas tivessem tido acesso a estas declarações de Saramago:

Vivo em um universo sem Deus mas, ao mesmo tempo, com Deus, porque o fato de Ele existir para os outros significa que Ele também existe para mim... e embora eu seja ateu, não posso ficar indiferente a textos tão imaginativos e belos. Nem meu ateísmo me impede de apreciar suas riquezas espirituais... Que aqueles que me censuram e me condenam escrevam sua própria visão de Jesus Cristo com a mesma sinceridade e dignidade com que eu escrevi a minha. (Pontiero, 1997b:75)

A atuação de Pontiero evidencia que, além de ser tradutor, ele teve um decisivo papel de mediação entre o autor e o público, além de influenciar nas decisões sobre quais obras traduzir. O fato

TradTerm, 15, 2009, p. 11-24 
de ele ter sido um tradutor que se expressava por meio de outros canais (por exemplo, textos acadêmicos e palestras sobre sua atividade) confere mais visibilidade ao tradutor, dando-lhe um lugar mais ativo na cultura. Pontiero frisa várias vezes a resistência do público de língua inglesa diante de literaturas estrangeiras, o que ele atribui muito mais a uma "intolerável falta de curiosidade sobre os estrangeiros e culturas diferentes" do que a um suposto status especial do inglês (Pontiero, 1997b:67). Assim, na visão de Pontiero, o tradutor amplia seu campo de ação na cultura, deixando de ser um agente passivo, que recebe um texto que um editor decidiu que deveria ser traduzido, para ajudar nessa própria decisão. Nas palavras dele, "em um equilibrismo delicado, o tradutor tenta fazer o melhor possivel tanto para o autor quanto para o editor, sem esquecer o leitor e sua satisfação pessoal" (Pontiero, 1997a:26).

\subsection{O tradutor defendendo uma voz autoral}

Pontiero tentava estabelecer contato com os autores que traduzia, e na maioria das vezes conseguiu. Até com a reclusa Clarice Lispector ele conseguiu contato, não sem primeiro ter insistido um bocado (Pontiero, 1997a:20). Com José Saramago, ele desenvolveu uma relação próxima e amigável. Segundo Pontiero, muitas vezes o tradutor pode se transformar num conselheiro do próprio autor, para o qual se revelam aspectos do texto que antes lhe passavam despercebidos (Pontiero, 1997a:24).

Um dos traços mais marcantes da escrita de Saramago são seus parágrafos muito longos, quase sem pontuação. Falta também uma pontuação convencional que defina diálogos e falas de personagens. O texto no início causa certo estranhamento, mas depois o leitor, se não desistir, acaba se acostumando. A única indicação de que houve uma alternância de falantes é uma frase começando com letra maiúscula no meio de um período. Assim, quando pensei na possibilidade de ver esse texto traduzido, a primeira coisa que me veio à mente foi se esse "formato" seria respeitado na tradução; se não haveria uma tendência por parte dos editores de editar esses longos parágrafos e diálogos neles incrustados. Mas basta folhear uma tradução de Pontiero para perceber rapidamente que ele manteve essa característica do texto de Saramago. Houve

TradTerm, 15, 2009, p. 11-24 
um incidente, é verdade, que mostra bem uma certa tirania dos editores e o empenho de Pontiero para fazer valer a sua tradução, que mantinha essa característica formal do texto de Saramago. Como narra Pontiero,

Reproduzi cuidadosamente esse estilo em minha tradução, mas acabei descobrindo, quando chegaram as provas, que o editor americano tinha introduzido uma pontuação convencional e a paragrafação dos diálogos, o que exigia toda forma de inserções no texto e a alteração da sintaxe. Meus protestos de nada valeram porque meu contrato não especificava o controle editorial final, e nem mesmo a reclamação do autor foi acatada. (Pontiero, 1997a:25)

Para se ter uma ideia da diferença que a intervenção do editor fez no texto, vale a pena trazer aqui um trecho do romance:

Baltasar and Blimunda sat in silence for a whole hour. Baltasar got up only once to put some wood on the dying fire, and Blimunda stirred once...

-I must go to Mafra, there I have my family, my parents, a sister.

- Stay here until you have to leave, there will always be time for you to return to Mafra.

- Why do you want me to remain here?

- Because it is necessary.

- You do not convince me.

- If you do not wish to remain, go away, then; I cannot force you to stay here...

They lay down together... (Pontiero, 1997a:25)

O texto da tradução, restaurado à sua forma original, trabalho que foi feito por Pontiero para uma segunda edição inglesa, ficou assim:

Baltasar and Blimunda sat in silence for a whole hour. Baltasar got up only once to put some wood on the dying fire, and Blimunda stirred once...I must go to Mafra, there I have my family, my parents, a sister, Stay here until you

TRADTERM, 15, 2009, p. 11-24 
have to leave, there will always be time for you to return to Mafra, Why do you want me to remain here, Because it is necessary, You do not convince me, If you do no wish to remain, go away, I cannot force you to stay here... They lay down together...(Idem)

Desse relato depreendem-se alguns fatos:

- Os editores às vezes interferem até no texto do autor e, ao que tudo indica, o texto do tradutor tende a merecer menos respeito ainda.

- Pontiero protestou diante da interferência do editor, defendendo uma voz autoral de Saramago que, ao mesmo tempo, também seria sua. Mais uma vez se observa um tradutor que é ativo em seu trabalho e que tem uma voz perante o autor, o editor e o leitor.

E por falar em voz, é interessante analisar, a partir desse relato, como Pontiero definia sua posição de tradutor. Ao mesmo tempo em que defendia um compromisso rigoroso com o texto de partida, Pontiero afirmava que o tradutor não é um mero transportador de significados, tendo uma função ativa no processo de tradução, como se pode ver por esses trechos:

Uma tradução de um romance não é nem uma reprodução nem uma cópia. (Pontiero, 1997a:21)

Nunca tomo liberdades com um texto no início, porque a principal preocupação do tradutor é, como também é o caso do próprio autor, com as palavras. (idem, ibidem:23)

Como tradutor você pode encontrar sua própria voz. (idem, ibidem:26)

Não dispensando o conceito de fidelidade, Pontiero ao mesmo tempo admite que o texto tem traços também do tradutor, já que é impossivel uma imparcialidade total por parte dele. Dessa forma, ele desenha para o tradutor literário um perfil mais huma-

TRADTERM, 15, 2009, p. 11-24 
no, mais visível e menos passivo, sem dispensar o compromisso com o autor e a obra original.

\section{A Título de Conclusão Provisória}

Este trabalho representa o início de uma pesquisa sobre as traduções de romances de José Saramago feitas por Giovanni Pontiero. Neste primeiro momento, deu-se um enfoque especial à prática tradutória de Pontiero e à sua atuação no campo editorial, sempre promovendo os interesses dos tradutores e dando-lhes uma voz. Em termos gerais, podemos observar um tradutor engajado em sua atividade, que reconhece as dificuldades da profissão, mas não assume uma posição lamentosa ou derrotista. No contato com os editores, Pontiero demonstrou ser combativo, empenhando-se para que a obra traduzida fosse bem acolhida pelo público, mas nem por isso se calando diante de intervenções exageradas, como aconteceu no caso da reformulação dos diálogos. Pontiero também se mostrou empenhado em difundir literaturas "menores", vendo com maus olhos a intolerância dos falantes de língua inglesa em geral para com linguas e literaturas que a eles desconhecidas. Além disso, em seus depoimentos e palestras, Pontiero ressaltava a importância de um "bom contrato", que estipularia, entre outras coisas, que ao tradutor coubesse a decisão final em relação ao texto.

Enfim, Pontiero é, sem dúvida, um exemplo. E antes de nos "defendermos", dizendo que ele ocupava um lugar privilegiado, que a ele foi concedida a honra de traduzir grandes autores, que em nosso país as condições são muito diferentes e piores, talvez fosse melhor pensarmos no que poderiamos fazer para nos tornarmos mais atuantes em nosso meio. Em vários de seus depoimentos, Pontiero insiste que a carreira acadêmica se casa perfeitamente com a tradução literária. Tendo o respaldo de um emprego seguro, o profissional pode fazer tradução em condições ideais, propor títulos, pesquisar a fundo o texto a ser traduzido e estabelecer o próprio ritmo de trabalho (Pontiero, 1997a:20, 21; idem, 1997b:59, 63). Tradutores que também ocupam uma posição no meio acadêmico provavelmente poderiam ousar um pouco mais e fazer valer essa "posição privilegiada", adaptando-a à sua realidade. Sem dúvida, as más condições de trabalho dos tradutores se devem, pelo menos em alguma medida, a uma passividade dos próprios tradutores.

TradTerm, 15, 2009, p. 11-24 


\section{Referências bibliográficas}

EOYANG, E. C. (2003) "Borrowed plumage": polemical essays on translation. Amsterdã e New York: Rodopi.

GRIFFIN, N. (1996) Obituary: Giovanni Pontiero. The Independent. Londres, 31/11. Disponivel em http://www.highbeam.com/doc/1P24767489.html. Acesso em 24/04/2008.

MILTON, J. (2002) O Clube do Livro e a tradução. Bauru-SP: EDUSC.

HOUAISS, A. (2008) Dicionário Houaiss da Língua Portuguesa - versão eletrônica. Disponivel em http://houaiss.uol.com.br/ busca.jhtm?verbete=nora\&cod=135781. Acesso em 11/06/2008.

PONTIERO, G. (1997a) Risks and rewards of literary translation. In: ORERO e SAGER (eds.) The translator's dialogue: Giovanni Pontiero. Amsterdam/Philadelphia: John Benjamins.

(1997b) Critical perceptions of Saramago's fiction. In: ORERO e SAGER (eds.) The translator's dialogue: Giovanni Pontiero. Amsterdam/Philadelphia: John Benjamins.

RABASSA, G. (2005) If this be treason - translation and it dyscontents, a memoir. New York: New Directons.

ROLLASON, C. (1998) Literature as History: José Saramago's O ano da morte de Ricardo Reis. Disponivel em http:// www.TheModernWord.com/borges/borges_papers_rollason. Acesso em 06/06/2008.

SAGER, J. C. (1997) Las traducciones al inglés de las novelas de José Saramago creadas por Giovanni Pontiero e su recepción em Inglaterra. Quaderns - Revista de traducció. vol. 10, pp. 111-120.

SARAMAGO, J. (2007) Ensaio sobre a cegueira. São Paulo: Companhia das Letras, $41^{a}$ reimpressão.

(1997) To write is to translate. In: ORERO e SAGER (eds.) The translator's dialogue: Giovanni Pontiero. Amsterdam/Philadelphia: John Benjamins.

TRadTerm, 15, 2009, p. 11-24 